\title{
EVALUATION OF STUDENTS' SOCIAL HAND WASHING KNOWLEDGE, PRACTICES, AND SKILLS IN A UNIVERSITY SETTING
}

\author{
Ahmet Ergin ${ }^{1}$, Mehmet Bostancı ${ }^{1}$, Özgür Önal' ${ }^{1}$, Ali İhsan Bozkurt', Nesrin Ergin ${ }^{2}$ \\ 'Pamukkale University, Faculty of Medicine, Department of Public Health, Denizli, Turkey \\ 2Denizli State Hospital, Denizli, Turkey
}

\begin{abstract}
SUMMARY
Background: Handwashing is an effective and inexpensive way to prevent diarrhea and acute respiratory infections. This study aimed to evaluate the Turkish University students' social hand washing knowledge, practices, skills and related factors.

Materials and methods: All existing 1st year students in the Medical and Educational Faculty, plus all existing 2nd and 3rd year students in the Medical Faculty of Pamukkale University, Denizli, Turkey, from April to May, 2010, were eligible for the study. Participants filled in a questionnaire. The questionnaire tested the students' social hand washing knowledge (8 questions), practices (21 questions), and skills (10 questions) and it was prepared using previously published studies. Participants received 1 point for each correct answer provided. Final scores were calculated by summing up the points from all questions in the particular section divided by the number of questions in this section and multiplied by 100. The Family Affluence Scale was used to determine a socioeconomic status (SES).

Results: In all 303 students participated in this study. Participants' age ( \pm SD) was $20.1 \pm 1.6$ and the age range was between 18 and 32 . Sixty two point seven percent of the participants were women. Forty four point nine percent of the participants were medical students. Fifty one point eight percent of the participants were in low SES. Twenty seven point four percent of the participants wash their hands less than 5 times a day. main reason for skipping hand washing was the participants' belief of 'no need' $(63.7 \%)$. The mean scores ( \pm SD) of participants' hand washing knowledge, practices, and skills were $71.2 \pm 20.7,60.3 \pm 13.4$ and $79.7 \pm 18.4$, respectively. All scores were significantly higher in women. A multivariate analysis showed that gender was the main factor affecting all scores.

Conclusions: Increasing quantity and/or quality of available campus based public health educational programs, creating hand-hygiene promotion programs to the general public and using the findings from this study are recommended.
\end{abstract}

Key words: hand hygiene, adolescents, social hand washing, education

Address for correspondence: A. Ergin, Department of Public Health, Faculty of Medicine, Pamukkale University, Bursa Cad. No: 119 Oda: 206, Kınıklı Denizli, Turkey. E-mail: aergin@pamukkale.edu.tr

\section{INTRODUCTION}

Infectious diseases are still the most common and deadly group of diseases for developing world. Annually, more than 3.5 million children under five die from diarrhea and acute lower respiratory-tract infections $(1,2)$. In case of proper hand washing there would be a significant reduction in the incidence of these diseases $(3,4)$. The first historical evidence on the importance of hand washing was revealed in a maternity clinic in Vienna in 1847. Cleaning hands by medical personnel reduced maternal mortality (5). Many other following studies indicated that handwashing reduced the spread of infectious diseases. Hospital acquired infections in the United Kingdom currently cost around $£ 1$ bn a year and affect nearly $10 \%$ of patients, causing over 5,000 deaths a year (more than deaths on the road) and taking up thousands of bed days. It has been suggested that the incidence of hospital acquired infection could potentially be cut by $15 \%$ if hand hygiene recommendations are implemented (6). A meta-analysis reported that failure to washing hands increased diarrheal diseases 1.8 times. Handwashing can reduce the risks of severe intestinal infections and shigellosis up to $48 \%$ and $59 \%$, respectively and it had a potential to avert a million diarrheal deaths annually (7). An interventional study showed that children younger than 15 years living in households that received handwashing promotion and plain soap had a $53 \%$ lower incidence of diarrhea than the controls (8). Another metaanalysis reported that all eligible studies showed a 6.0 to $44.0 \%$ reduction in respiratory diseases with proper handwashing (9).

Currently, proper handwashing is not as widespread as desired worldwide. It has been reported that the frequency of hand washing with soap before handling food or after using a toilet was observed in only between $0 \%$ and $34.0 \%$ cases (4). Center for Disease Control and Association for Professionals in Infection Control and Epidemiology have created guidelines for hand washing (10). In addition, in order to emphasize the importance of hand washing, October 15 has been declared as the Global Hand Washing Day by UNICEF since 2008 (11). Our study evaluated university students' social hand washing knowledge, practices and skills and other related factors in a Turkish university setting. 


\section{MATERIAL AND METHODS}

The sampling frame consisted of all existing 1st year students in the Medical and Educational Faculty, plus all existing 2nd and 3rd year students in the Medical Faculty of Pamukkale University, Denizli, Turkey. There was not any sample selection procedure; we intended to reach everybody in the sampling frame. This approach was mainly aimed to include an equal number of students from both Faculties in the final sample. The study was conducted from April to May, 2010. All necessary permissions from the University management and verbal consents from all participants were obtained. 'Social hand washing' in this study was defined as a mechanical cleaning process, specifically removing dirt and pathogenic bacteria by using water and solid or liquid soap with no antiseptic properties (12). Participants were asked to fill in a questionnaire. The questionnaire was prepared by using previously published studies $(4,10,13,14)$. The questionnaire included questions on student's socio-demographic characteristics and information on students' social hand washing knowledge, practices, and skills. It was piloted on a small group of students from another Faculty before the study. There were 8 questions to evaluate hand washing knowledge, 21 questions to assess hand washing practice, and 10 questions to estimate hand washing skills. Participants received 1 point for each correctly answered question concerning their knowledge, practice and skill in respect of investigated issue. Final scores were calculated by summing up the points from all questions in the particular section divided by number of the questions in this section and multiplied by 100 . Correct responses for social hand washing knowledge questions were 'disagree' responses for 1st, 3rd, 4th, and 6th propositions, and 'agree' responses for the $2 \mathrm{nd}, 5 \mathrm{th}, 7 \mathrm{th}$, and 8 th propositions in Table 2. Correct responses for social hand washing practice questions were 'never' responses for 3rd, 6th, 11th, and 'always' responses for the rest of the questions in the Table 3 . In the evaluation of social hand washing skill score, only 'always' response received 1 point for all questions. The socio-economic status (SES) of the participant was determined by using the Family Affluence Scale (FAS) (15). The FAS score was determined by recoding the eight point scores ( 0 to 7$)$ into three categories [low (0-3), middle (4-5) and high (6-7) FAS level].

SPSS for Windows 17th Version was used for statistical analysis. Percentages and means were calculated as usual. Student t-test and ANOVA were used for determining the differences between means where appropriate. A linear regression model was the method of choice in order to see the unconfounded associations.

\section{RESULTS}

In total 303 students participated in the study, the mean age $( \pm$ SD) was $20.1 \pm 1.6$. The age range was between 18 and 32. Sixty two point seven percent of the participants were women. Forty four point nine percent of the participants were medical students. Sixty seven point six percent of the students were in their 1st year in both Faculties; and $18.2 \%$, in their 2nd; $14.2 \%$, in their 3rd year in the Medical Faculty. Distribution of participants by SES was as follows: fifty one point eight percent of the participants fall in low, $37.0 \%$, in middle, and $11.2 \%$, in high SES category.
Twenty seven point one percent of the participants wash their hands 11 times and more a day. Forty five point five percent wash their hands 6-10 times a day. Twenty seven point four percent wash their hands less than 5 times a day. Table 1 listed the reasons for skipping hand washing as 'far from the sink' (3.0\%), 'lack of time' $(2.3 \%)$, 'afraid of the side effects of hand washing' (6.6\%), 'forgetting' (19.5\%), and 'no need' (63.7\%).

The distribution of answers with regards to hand washing knowledge, practices and skills questions are displayed in Table 2, Table 3, and Table 4, respectively. The tables show that a significant number of participants failed to provide correct answers to the questions on hand washing.

Table 5 shows that the mean $( \pm \mathrm{SD})$ scores of participants' hand washing knowledge, practice and skill are $71.2 \pm 20.7,60.3 \pm 13.4$, and $79.7 \pm 18.4$, respectively. Hand washing knowledge, practice and skill scores in women are significantly different from the scores of men (all p-values $<0.001$ ). The mean score of participants' hand washing knowledge in Educational Faculty students is higher than that in Medical students, however it was not statistically significant $(\mathrm{p}>0.05)$. Similarly, the mean of hand washing practice and skill scores was higher in the former group and it was significantly different (both p-values $<0.001$ ). Living location made only several differences on the practice scores. There was no association between SES of students and hand washing knowledge, practice and skill scores.

Table 6 indicates that gender was the main factor related to the students' hand washing knowledge, practice and skill scores in the regression analysis. Student's type of study also affected student's hand washing practice and skill scores.

\section{DISCUSSION}

This study examined university students' social hand washing knowledge, practices and skills. It also determined the associations with some socio-demographic features. It is not possible to define the universally recommended number of daily hand washings to ensure proper hand hygiene as it depends on type of daily activities, however, approximately one third of the students

Table 1. Answers to the questions about participants' hand washing

\begin{tabular}{|l|l|c|}
\hline Questions & Answers & $\begin{array}{c}\mathbf{N}=303 \\
\mathbf{n}(\%)\end{array}$ \\
\hline \multirow{4}{*}{$\begin{array}{l}\text { How many times a day do you } \\
\text { wash your hands? }\end{array}$} & Never & $2(0.7)$ \\
\cline { 2 - 3 } & $1-2$ times & $3(1.0)$ \\
\cline { 2 - 3 } & $3-5$ times & $78(25.7)$ \\
\cline { 2 - 3 } & 6-10 times & $138(45.5)$ \\
\cline { 2 - 3 } handwashing & 11 and over & $82(27.1)$ \\
\hline Main reason for skipping & Far from the sink & $9(3)$ \\
\cline { 2 - 3 } & No need & $193(63.7)$ \\
\cline { 2 - 3 } & No time & $7(2.3)$ \\
\cline { 2 - 3 } & Side effects & $20(6.6)$ \\
\cline { 2 - 3 } & Keep forgetting & $59(19.5)$ \\
\cline { 2 - 3 } & Others & $15(5)$ \\
\hline
\end{tabular}


Table 2. Answers to the questions about participants' hand washing knowledge

\begin{tabular}{|c|c|c|c|}
\hline & $\begin{array}{l}\text { Agree } \\
\mathrm{n}(\%)\end{array}$ & $\begin{array}{c}\text { Disagree } \\
\mathrm{n}(\%)\end{array}$ & $\begin{array}{c}\text { Do not know } \\
n(\%)\end{array}$ \\
\hline 1. Cold water should be used for hand washing. & $76(25.1)$ & $132(43.6)$ & $95(31.4)$ \\
\hline 2. Medium hot water should be used for hand washing. & $223(73.6)$ & $27(8.9)$ & $53(17.5)$ \\
\hline 3. Hot water should be used for hand washing. & $91(30)$ & $141(46.5)$ & $71(23.4)$ \\
\hline 4. No need to remove watch and bracelets. & $76(25.1)$ & $200(66.0)$ & $27(8.9)$ \\
\hline 5. Needs to remove rings. & $225(74.3)$ & $59(19.5)$ & $19(6.3)$ \\
\hline 6. No need to wash wrists. & $24(7.9)$ & $268(88.4)$ & $11(3.6)$ \\
\hline 7. Hands need to be washed at least 15 seconds. & $257(84.8)$ & $21(6.9)$ & $25(8.3)$ \\
\hline 8. Need drying after washing the hands. & $281(92.7)$ & $12(4)$ & $10(3.3)$ \\
\hline
\end{tabular}

A bold number indicates the appropriate answer for this specific question.

Table 3. Answers to the questions about participants' hand washing practices

\begin{tabular}{|c|c|c|c|}
\hline & $\begin{array}{c}\text { Always } \\
\mathrm{n}(\%)\end{array}$ & $\begin{array}{c}\text { Sometimes } \\
n(\%)\end{array}$ & $\begin{array}{l}\text { Never } \\
\mathrm{n}(\%)\end{array}$ \\
\hline 1. I wash my hands before meals. & $214(70.6)$ & $85(28.1)$ & $4(1.3)$ \\
\hline 2. I wash my hands after meals. & $226(74.6)$ & $77(25.4)$ & $0(0.0)$ \\
\hline 3. I wash my hands before using restroom. & $72(23.8)$ & $161(53.1)$ & $70(23.1)$ \\
\hline 4. I wash my hands after using restroom. & $286(94.4)$ & $14(4.6)$ & $3(1.0)$ \\
\hline 5. I wash my hands when come home. & $203(67)$ & $92(30.4)$ & $8(2.6)$ \\
\hline 6. I wash my hands after handshaking. & $52(17.2)$ & $178(58.7)$ & $73(24.1)$ \\
\hline 7. I wash my hands before going to bed & $121(39.9)$ & $151(49.8)$ & $31(10.2)$ \\
\hline 8. I wash my hands after using public transportation. & $160(52.8)$ & $123(40.6)$ & $20(6.6)$ \\
\hline 9. I wash my hands after waking up in the morning. & $243(80.2)$ & $52(17.2)$ & $8(2.6)$ \\
\hline 10. I wash my hands after touching animals. & $275(90.8)$ & $24(7.9)$ & $4(1.3)$ \\
\hline 11. I wash my hands only if they are soiled. & $291(96)$ & $11(3.6)$ & $1(0.3)$ \\
\hline 12. I wash my hands before preparing meals. & $268(88.4)$ & $29(9.6)$ & $6(2.0)$ \\
\hline 13. I wash my hands after money exchange. & $148(48.8)$ & $131(43.2)$ & $24(7.9)$ \\
\hline 14. I wash my hands after blowing the noose. & $266(87.8)$ & $32(10.6)$ & $5(1.7)$ \\
\hline 15. I wash my hands after touching garbage. & $289(95.4)$ & $14(4.6)$ & $0(0.0)$ \\
\hline 16. I wash my hands before touching sick people. & $119(39.3)$ & $151(49.8)$ & $33(10.9)$ \\
\hline 17. I wash my hands after touching sick people. & $216(71.3)$ & $73(24.1)$ & $14(4.6)$ \\
\hline 18. I wash my hands after combing my hair. & $94(31.0)$ & $153(50.5)$ & $56(18.5)$ \\
\hline 19. I wash my hands after cleaning my home. & $262(86.5)$ & $34(11.2)$ & $7(2.3)$ \\
\hline 20. I wash my hands after washing dishes. & $256(84.5)$ & $38(12.5)$ & $9(3.0)$ \\
\hline 21. I wash my hands after doing laundry. & $218(71.9)$ & $51(16.8)$ & $34(11.2)$ \\
\hline
\end{tabular}

A bold number indicates the appropriate answer for this specific question.

in this study wash their hands less than 5 times a day which is possible an insufficient number for proper hand hygiene. Most of the participants washed their hands 6-10 times a day. Although it has been completed in a different population in this country in 2009 , another study determined only $41.5 \%$ of participants washing their hands 11 times a day which was recommended ast the cut off point for proper hand washing in the study (14). These findings may indicate widespread insufficient hand hygiene in this population. Also, low scores related to participants' social hand washing knowledge, practice and skills may indicate a need of an extensive public health education program on the topic.
Our study also indicated that the main reasons for skipping hand washing were participant's believes of 'no need' and 'keep forgetting'. Another study encompassing health workers inquired about the reasons for not washing their hands pointed out similar attitudes such as 'not think about it at the moment, forgetting, and being busy' (16). In another study, the most frequent responses were 'no need' and 'lack of time' (14). Other relevant studies on hand washing showed that 'skin drying effect of hand hygiene products, soap or paper towels unavailability', 'lack of time', 'lack of knowledge', 'not thought and forgotten', 'lack of role models in school or among adults' were the main obstacles in 
Table 4. Answers to the questions about participants' hand washing skills

\begin{tabular}{|c|c|c|c|}
\hline & $\begin{array}{c}\text { Always } \\
\mathrm{n}(\%)\end{array}$ & $\begin{array}{c}\text { Sometimes } \\
n(\%)\end{array}$ & $\begin{array}{l}\text { Never } \\
\mathrm{n}(\%)\end{array}$ \\
\hline 1. Folding sleeves and removing jewellery such as watch and rings & $156(51.5)$ & $119(39.3)$ & $28(9.2)$ \\
\hline 2. Getting some soup a hand & $278(91.7)$ & $22(7.3)$ & $3(1.0)$ \\
\hline 3. Turning the faucet on & $288(95.0)$ & $13(4.3)$ & $2(0.7)$ \\
\hline 4. Making soap lather with some water & $289(95.4)$ & $13(4.3)$ & $1(0.3)$ \\
\hline 5. Turning off the faucet and rubbing the hands & $196(64.7)$ & $77(25.4)$ & $30(9.9)$ \\
\hline 6. Clenching the fingers cleaning between the fingers of both hands (without forgetting the thumb) & $226(74.6)$ & $72(23.8)$ & $5(1.7)$ \\
\hline 7. Cleaning hands by rubbing wrists & $186(61.4)$ & $107(35.3)$ & $10(3.3)$ \\
\hline 8. Turning on the faucet and washing hands by rubbing and removing all foam on hands & $272(89.8)$ & $28(9.2)$ & $3(1.0)$ \\
\hline 9. Shedding some water on the tap and turning it off & $255(84.2)$ & $43(14.2)$ & $5(1.7)$ \\
\hline 10. Drying hands & $274(90.4)$ & $28(9.2)$ & $1(0.3)$ \\
\hline
\end{tabular}

A bold number indicates the appropriate answer for this specific question.

Table 5. Participants' hand washing knowledge, practice, and skill scores by some socio-demographics features

\begin{tabular}{|c|c|c|c|c|c|}
\hline Variables & & $n(\%)$ & $\begin{array}{l}\text { Knowledge score } \\
\text { Mean士SD }\end{array}$ & $\begin{array}{l}\text { Practice score } \\
\text { Mean } \pm S D\end{array}$ & $\begin{array}{l}\text { Skill score } \\
\text { Mean } \pm S D\end{array}$ \\
\hline \multirow[t]{2}{*}{ Gender } & Women & $113(37.3)$ & $65.5 \pm 24.0$ (1) & $63.3 \pm 11.8(1)$ & $82.7 \pm 16.0(1)$ \\
\hline & Men & $190(62.7)$ & $74.6 \pm 17.7(1)$ & $55.4 \pm 14.3(1)$ & $75.0 \pm 23.2(1)$ \\
\hline \multirow[t]{2}{*}{ Department } & Education & $167(55.1)$ & $71.6 \pm 19.4$ & $62.8 \pm 13.3(1)$ & $83.8 \pm 17.1(1)$ \\
\hline & Medicine & $136(44.9)$ & $70.8 \pm 22.3$ & $57.2 \pm 12.8(1)$ & $75.0 \pm 20.9(1)$ \\
\hline \multirow[t]{6}{*}{ Living Location } & With family & $76(25.1)$ & $75.0 \pm 18.3$ & $61.6 \pm 12.7(1)$ & $79.7 \pm 19.1$ \\
\hline & Dormitory & $94(31)$ & $73.0 \pm 18.1$ & $61.4 \pm 14.2(2)$ & $81.5 \pm 18.4$ \\
\hline & Relatives & $7(2.3)$ & $55.4 \pm 23.7$ & $53.9 \pm 18.8(3)$ & $78.6 \pm 37.6$ \\
\hline & With friends & 99 (32.7) & $68.5 \pm 23.1$ & $57.2 \pm 12.6(1,2)$ & $77.1 \pm 19.4$ \\
\hline & Alone & $21(6.9)$ & $66.6 \pm 24.8$ & $63.4 \pm 11.9$ & $84.7 \pm 16.9$ \\
\hline & Other & $6(2)$ & $75.0 \pm 19.4$ & $74.2 \pm 4.7(1,2,3)$ & $85.0 \pm 16.4$ \\
\hline \multirow{3}{*}{$\begin{array}{l}\text { Socioeconomic status } \\
\text { (SES) }\end{array}$} & Low & $157(51.8)$ & $70.5 \pm 21.7$ & $59.0 \pm 12.9$ & $80.7 \pm 18.9$ \\
\hline & Middle & $112(37.0)$ & $72.8 \pm 19.4$ & $61.7 \pm 13.8$ & $79.6 \pm 20.4$ \\
\hline & High & 34 (11.2) & $69.5 \pm 21.1$ & $61.5 \pm 13.8$ & $76.8 \pm 17.9$ \\
\hline \multicolumn{2}{|l|}{ Total } & 303 & $71.2 \pm 20.7$ & $60.3 \pm 13.4$ & $79.7 \pm 18.4$ \\
\hline
\end{tabular}

$(1),(1,2),(2),(3),(1,2,3)=p<0,05, p$-values come from either a t-test or a posthoc ANOVA test.

promoting hand washing as the habit of proper hand hygiene $(14,16-18)$.

The highest number of participants in this study correctly stated that one should dry his hands after washing. However most of them did not know that the temperature of the water was an important factor for hand hygiene. Also, the high number of participants stated that they wash their hands after handling garbage and wash their hands after using a toilet. Another study showed that most of the participants wash their hands after using restrooms (14). Not surprisingly, number of participants who claimed that 'washing hands before meals' was lower than in those claiming 'washing hands after using restrooms'. Larson et al. performed a study where participants were asked similar questions on hand washing. 'Washing hands after using restrooms received full marks, however 'washing hands before meals' scored less (17).
In this study, the associations between participants' social hand washing knowledge, practice and skill scores, type of Faculty, living location and SES were evaluated. A multivariate analysis showed that gender was the main factor affecting these three scores. Study on the topic did not show any difference between women and men, however it showed significantly more positive attitude scores in women (14). However, study from Africa did not show any difference in frequency of hand washing between genders (19). Participants' type of the study was also associated with the scores in the current study. Although, the knowledge score was insignificantly higher in the Educational Faculty students, practice and skill scores were significantly higher among the students of Educational Faculty. Surprisingly, a study evaluated the compliance to hand hygiene guidelines among health care workers and the medical students were found to be the most compliant (18). This was contrary to our findings and it may indicate a need for further studies on the topic. 
Table 6. Multivariate analysis for determining associations between hand washing knowledge, practice, and skill scores and some socio-demographics features

\begin{tabular}{|c|c|c|c|c|}
\hline Variables & В & SE & $95 \% \mathrm{Cl}$ for $\beta$ & $\mathrm{p}$-value* \\
\hline \multicolumn{5}{|c|}{ Knowledge score } \\
\hline Gender & 9.0 & 2.4 & $4.2-13.7$ & $<0.001$ \\
\hline \multicolumn{5}{|c|}{ Practice score } \\
\hline Gender & 7.1 & 1.6 & $3.9-10.4$ & $<0.001$ \\
\hline Department & -5.5 & 1.6 & $-8.7-(-2.3)$ & 0.001 \\
\hline Age & 1.3 & 0.5 & $0.4-2.2$ & 0.004 \\
\hline SES & 0.8 & 0.4 & $0.03-1.7$ & 0.042 \\
\hline \multicolumn{5}{|c|}{ Skill score } \\
\hline Department & -8.6 & 2.3 & $-13.2-(-4.0)$ & $<0.001$ \\
\hline Gender & 6.7 & 2.3 & $2.0-11.0$ & 0.005 \\
\hline Age & 1.6 & 0.6 & $0.3-2.9$ & 0.017 \\
\hline
\end{tabular}

${ }^{*} \mathrm{p}$-values come from a stepwise linear regression model. The model started with gender, age, department, living accommodation and socioeconomic status (SES).

There are several limitations of the study. One important limitation was the way of selection of the study group. In addition to all first year students from both Faculties, we also included the 2nd and 3rd year medical students in the study because of the low number of students in the Medical Faculty classes. However, we analyzed the data using only the 1st year students from both Faculties and verified the results. In addition, we used a multivariate analysis and included age, as a proxy to class variable, in order to adjust the findings. Secondly, we did not use a structured observation in order to determine the participants' hand washing skills. Logistic concerns were the main reason for this approach. We were inclined to consider this population as highly educated and capable to evaluate their attitudes as to their hand washing skills.

In conclusion, we need to find a way to improve hand hygiene of our students. It is also possible to say that gender is the most significant factor related to every aspect of hand hygiene. Therefore, supporting quantity and/or quality of available campus based public health education programs, development of hand-hygiene promotion programs for the general public and use of the findings from this study is recommended.

\section{Acknowledgement}

We would like to thank to Feride Marım, Özgün Taban, Zahide Naml, Elif Dilasa Pala, Pınar Yıldırım, Recep Yıldırım, Sezai Üstün Aydın.

\section{Conflict of interest}

None.

\section{REFERENCES}

1. World Health Organization. World Health Report 2005: make every mother and child count. Geneva: WHO; 2005.

2. Beumer R, Bloomfield SF, Exner M, Fara GM, Nath KJ, Scott EA. Hygiene procedures in the home and their effectiveness: a review of the scientific evidence base [Internet]. International Scientific Forum on Home Hygiene; 2008 [cited 2010 Dec 4]. Available from: http:// www.ifh-homehygiene.org/IntegratedCRD.nsf/f5236e2da2822fef8025750b000dc985/C9BF235B5D76AD09802572970063C5D8/\$File/ hygprocevbasefinal2.pdf.

3. Hand washing: reducing the risk of common infections [Internet]. Hamilton: Canadian Center for Occupational Health and Safety; 2011 [cited
2011 Jan 4]. Available from: http://www.ccohs.ca/oshanswers/diseases/ washing_hands.html.

4. The Handwashing handbook: a guide for developing a hygiene promotion program to increase handwashing with soap [Internet]. Washington: World Bank; 2005 [cited 2010 Dec 28]. Available from: http://vle.worldbank. $\mathrm{org} / \mathrm{bnpp} / \mathrm{en} / \mathrm{publications/energy-water/the-handwashing-handbook-a-}$ guide-developing-a-hygiene-promotion-program-in.

5. Jarvis WR. Handwashing-the Semmelweis lesson forgotten? Lancet. 1994 Nov 12;344(8933):1311-2.

6. Teare L, Cookson B, Stone S. Hand hygiene. BMJ. 2001 Aug 25;323(7310):411-2.

7. Curtis V, Cairncross S. Effect of washing hands with soap on diarrhoea risk in the community: a systematic review. Lancet Infect Dis. 2003 May;3(5):275-81.

8. Luby SP, Agboatwalla M, Painter J, Altaf A, Billhimer WL, Hoekstra RM. Effect of intensive handwashing promotion on childhood diarrhea in high-risk communities in Pakistan: a randomized controlled trial. JAMA. 2004 Jun 2;291(21):2547-54.

9. Rabie T, Curtis V. Handwashing and risk of respiratory infections: a quantitative systematic review. Trop Med Int Health. 2006 Mar;11(3):258-67.

10. Boyce JM, Pittet D; Healthcare Infection Control Practices Advisory Committee; HICPAC/SHEA/APIC/IDSA Hand Hygiene Task Force. Guideline for Hand Hygiene in Health-Care Settings. Recommendations of the Healthcare Infection Control Practices Advisory Committee and the HICPAC/SHEA/APIC/IDSA Hand Hygiene Task Force. Society for Healthcare Epidemiology of America/Association for Professionals in Infection Control/Infectious Diseases Society of America. MMWR Recomm Rep [Internet]. 2002 Oct 25 [cited 2010 Dec 6]; 51(RR-16):1-45. Available from: http://www.cdc.gov/mmwr/PDF/rr/rr5116.pdf.

11. Global Handwashing Day 15 October: planner's guide. Health in your hands: a public - private partnership [Internet]. [cited 2010 Dec 7]. Available from: http://www.globalhandwashingday.org/Planners_Guide_Global Handwashing Day.pdf.

12. Dirican R, Bilgel N. Personal health protection measures. Public Health (Community Medicine). 2nd ed. Bursa: Uludag University Printing House; 1993. (In Turkish.)

13. Clean hands save lives. Handwashing fact sheet [Internet]. [cited 2010 Dec 7]. Available from: www.cdc.gov/h1n1flu/pdf/handwashing.pdf.

14. Uner S, Sevencan F, Basaran E, Balci C, Bilaloglu B. Determining of persons' knowledge and attitudes on social hand washing who were admitted to a primary health care center. TAF Prev Med Bull. 2009;8(3):207-16. (In Turkish.)

15. Currie CE, Elton RA, Todd J, Platt S. Indicators of socioeconomic status for adolescents: the WHO Health Behaviour in School-aged Children Survey. Health Educ Res. 1997 Sep;12(3):385-97.

16. Pittet D, Mourouga P, Perneger TV. Compliance with handwashing in a teaching hospital. Infection Control Program. Ann Intern Med. 1999 Jan 19;130(2):126-30.

17. Larson EL, Bryan JL, Adler LM, Blane C. A multifaceted approach to changing handwashing behavior. Am J Infect Control. 1997 Feb;25(1):3-10. 
18. Pittet D, Simon A, Hugonnet S, Pessoa-Silva CL, Sauvan V, Perneger TV. Hand hygiene among physicians: performance, beliefs, and perceptions. Ann Intern Med. 2004 Jul 6;141(1):1-8.

19. World Health Organization. Baseline survey report: topic: risk factors influencing children's healthy environment in Kaplamai division TransNzoia district [Internet]. Nairobi: Division of environmental health [cited 2010 Nov 7]. Available from: www.who.int/entity/heca/activities/ Kenya1 baseline survey.pdf.

Received January 24, 2011 Accepted in revised form August 12, 2011 